\title{
Kurasi Fashion: Model Bingkai Kurasi pada Jember Fashion Carnival
}

\author{
Suharno, Cahyadi Dewanto \\ Program Studi Tata Rias dan Busana, Program Studi Televisi dan Film \\ Fakultas Seni Rupa dan Desain, Fakultas Media dan Budaya \\ Institut Seni Budaya Indonesia (ISBI) Bandung \\ Jalan Buahbatu 212 Bandung, 40265 \\ Email: bjrianto@gmail.com; art_inc_7@yahoo.co.id
}

\begin{abstract}
This research is based on empirical facts, that until now there is no a carnival fashion curation model that can be used as a subject of study and a practical guide curation of a carnival fashion. Therefore, this study aims to formulate a model used as an important part of fashion events, that not only offer artworks, but also a discourse that can be scientifically accountable. For this purpose, the object of this research is the event of Jember Fashion Carnival (JFC). This choice is based on the fact that JFC is the 3rd largest fashion carnival of the world, and the concept of its curation has not been studied. The formal object is phenomenology; an approach that emphasizes a direct observation in the field, and its data analysis is interpretative. This approach focuses on the ideology of curation, while emphasizing the involvement of researchers in clarifying assumptions and offering new perspectives. The results of this study is a model for a curation fashion carnival that can be used by a fashion curator to curate fashion events, especially in a fashion carnival.
\end{abstract}

Keywords: curation, fashion, carnival, model

\begin{abstract}
ABSTRAK
Penelitian ini didasarkan pada fakta empirik bahwa hingga kini belum ada model kurasi fashion carnival yang dapat menjadi bahan kajian, dan panduan praktik kurasi fashion carnival. Oleh sebab itu, penelitian ini bertujuan merumuskan model tersebut agar menjadi bagian penting dari perhelatan fashion yang bukan hanya menawarkan karya, namun juga wacana yang dapat dipertanggungjawabkan secara ilmiah. Untuk kepentingan tersebut, objek material penelitian ini adalah perhelatan Jember Fashion Carnival (JFC). Pilihan ini didasarkan pertimbangan bahwa JFC merupakan karnaval fashion terbesar ke-3 dunia, dan konsep kurasinya belum ada yang meneliti. Adapun objek formalnya adalah fenomenologi; sebuah pendekatan yang menekankan observasi langsung di lapangan dan analisa datanya bersifat interpretatif. Pendekatan ini memusatkan perhatian pada ideologi pengkurasi, sekaligus menekankan keterlibatan peneliti dalam memperjelas asumsi dan menawarkan perspektif baru. Hasil penelitian ini adalah model kurasi fashion carnival yang dapat digunakan kurator fashion untuk mengkurasi perhelatan fashion, khususnya fashion carnival.
\end{abstract}

Kata kunci: kurasi, fashion, karnaval, model 


\section{PENDAHULUAN}

Tidak dapat dipungkiri bahwa saat ini fashion dianggap sebagai kekuatan budaya penting dan menjadi objek studi yang serius. Breward (2003: 9) mencatat bahwa fashion telah menjadi objek studi setara dengan bentuk seni populer lainnya. Pernyataan ini cukup beralasan, karena seni telah lama mempengaruhi fashion. Sejak awal abad ke-20, gaya lukisan neoplastic telah mempengaruhi fashion di Eropa. Neoplastic adalah gaya atau aliran dalam seni rupa abstrak yang digagas Piet Mondrian. Gaya ini menyatukan high art dan popular culture (Troy, 2006: 15-36). Penyatuan fashion dengan seni rupa secara tegas dicatat Palmor (2015: 40), bahwa gaya Mondrian dalam fashion telah ada sejak 2 Agustus 1965.

Salah satu desainer fashion yang cukup fenomenal dalam menerjemahkan gaya neoplastic ke dunia fashion adalah Yves Saint Laurent. Kreativitas Laurent bahkan menjadikan Carla Bruni menyebutkan, "With Saint Laurent, art became fashion" (Klein, 2015). Melalui kreativitasnya, Laurent melahirkan karya-karya fashion yang mencerminkan aliran dalam seni rupa modern, yakni dari modernisme, impresionisme, hingga pop art. Hal ini pulalah yang menjadi landasan pernyataan Tsotsos (2014: 2), bahwa para desainer kontemporer telah mengonfigurasi metode penyajian fashion dari tradisional menjadi modern.

Ketika fashion menjelma menjadi bentuk seni, keberadaan kurator fashion menjadi penting. Hal ini dikarenakan kuratorlah yang membangun dialog untuk menyatukan karya-seniman dengan pasar-mediapublik dalam suatu wacana-suasana-tempat pameran (Susanto, 2004: 7). Kurator adalah sosok penting yang memiliki kuasa mengolah citra karya di ruang pameran, sehingga ada pepatah yang mengatakan,"behind every great artist is a great curator."

Fenomena fashion menjelma menjadi bentuk seni juga menjadi tantangan besar bagi museum dan galeri. Craik (2009: 187) menjelaskan, tantangan tersebut adalah bagaimana menampilkan fashion yang tidak lagi hanya dianggap sebagai artefak yang menarik dan mewakili periode budaya tertentu, namun disajikan sebagai bentuk seni dengan memperhatikan garis, bentuk, warna, dan sebagai obyek kinestetik, serta ditempatkan dalam konteks sosial dan budaya sebagai simbol trend tertentu.

Persoalannya, praktik kerja kurasi dalam perhelatan fashion yang menempatkanfashion, desainer, dan publik dalam konteks kuratorial adalah hal yang baru. Hal ini dapat dipahami karena istilah fashion curation sendiri juga masih baru sebagaimana istilah fashion theory (Buick, 2012: 91-92). Apalagi praktik kurasi di ranah seni rupa di Indonesia baru mulai secara nyata pada dekade 90an. Sudah barang tentu hal ini mempengaruhi kelangkaan pustaka kurasi fashion di Indonesia. Konsekuensi logisnya, konsep kurasi pameran fashion yang dapat dijadikan bahan kajian ilmiah dan panduan praktik kurasi fashion sulit didapat.

Berdasarkan hal di atas, tujuan penelitian ini adalah untuk merumuskan konsep bingkai kurasi fashion yang dapat dijadikan rujukan praktik kurasi fashion yang profesional, khususnya untuk kepentingan karnaval. Hal ini mendasar karena pustaka tentang kuratorial yang ada lebih bicara soal kurasi seni rupa, belum menyentuh kurasi fashion (periksa misalnya Hujatnikajennong, 2015 dan Susanto, 2004). Walaupun demikian, bukan berarti penelitian ini tidak penting bagi praktik kurasi fashion di luar karnaval. Hal ini dikarenakan praktik kurasi pada intinya adalah menyatukan karya, seniman, dan publik dalam bingkai wacana tertentu yang diusung kurator dalam ruang perhelatan seni, seperti di galeri, museum, jalanan, dan lain sebagainya.

Untuk keperluan di atas, objek material dalam penelitian ini adalah perhelatan karnaval di Jember Fashion Carnival (JFC), 
sebuah perhelatan karnaval tahunan kelas dunia yang persoalan kurasinya belum disentuh peneliti lain. Peneliti terdahulu lebih menyoroti aspek di luar kurasi fashion, seperti konstruksi identitas (Jannah, 2012: 135-152), branding kota Jember (Cahyani, 2015), dan intertekstualitas dari JFC (Denisa, 2016: 430-443). Selanjutnya, perhelatan JFC yang dikaji adalah karnaval dua tahun terakhir, yakni JFC ke-15 (2016) yang mengusung tema Revival, dan JFC ke-16 (2017) yang mengusung tema Victory. Dua perhelatan ini dipandang cukup untuk melihat garis besar kurasi dalam situasi yang berbeda.

\section{METODE}

Penelitian ini adalah investigasi yang sistematis, terkontrol, empiris, dan kritis terhadap kurasi fashion dalam kaitannya dengan fenomena kurasi di JFC. Mengingat penelitian ini ingin menjawab pertanyaan mendalam, detail, dan khusus, maka digunakan paradigma kualitatif yang menekankan pada pemahaman konsep kurasi fashion di JFC dan eksekusinya berdasarkan kondisi realitas atau natural setting yang holistis, kompleks, dan rinci. Oleh sebab itu, digunakan pendekatan fenomenologi sebagaimana dimaksud oleh Brouwer (1984: 3-4), yakni "a way of looking at think" yang berbeda. Brouwer menganalogikan tidak mungkin memaksa orang buta memahami bahwa ada banyak warna kuning pada sebuah lukisan karena orang tersebut tidak melihatnya. Cara terbaiknya adalah mengikuti deskripsi warna kuning yang digambarkan oleh orang tersebut. Creswell (1998:15) menyebut situasi ini dengan situasi alami. Situasi alami dalam konteks penelitian ini adalah kondisi alami dari praktik kurasi di JFC. Alami, artinya tanpa dikondisikan oleh peneliti, sehingga data yang diperoleh benar-benar murni tanpa dipengaruhi oleh peneliti.

Adapun langkah-langkah penelitian yang dilakukan adalah pengumpulan data, analisis, dan penarikan simpulan. Data dalam penelitian ini diperoleh dari studi pustaka, studi piktorial, dan studi lapangan. Studi pustaka dilakukan untuk melacak praktik kurasi fashion dari perspektif teoritik. Studi piktorial dilakukan untuk mendapatkan data visual tekait praktik kurasi fashion di JFC yang telah dilakukan. Studi lapangan dilakukan untuk mendapatkan data kongkrit kekinian terkait praktik kurasi di JFC. Analisis data dilakukan dengan mereduksi dan mengolah data agar diperoleh data yang relevan dengan aspek keapaan, kemengapaan, kebagaimanaan, dan kemanaan dari konsep kurasi fashion.

\section{HASIL DAN PEMBAHASAN \\ Perhelatan Fashion}

Perhelatan fashion adalah bentangan teks, dan kurator bertugas menenun, memaknai, dan menarasikan untaian teks tersebut kepada publik. Perhelatan ini setidaknya ada tiga jenis, yakni pameran fashion, fashion show, dan fashion carnival. Ketiga perhelatan ini dibingkai dengan tema tertentu yang merupakan payung wacana dari perhelatan tersebut.

Pameran fashion adalah karya fashion yang dipamerkan di ruang galeri, museum, dan ruang alternatif lainnya. Pada umumnya pameran ini tidak memerlukan model untuk memajang karya. Hal ini berbeda dengan fashion show yang harus menggunakan model saat mempertunjukkan fashion dalam ruang dan waktu tertentu. Adapun karnaval fashion adalah perhelatan yang menampilkan karya fashion secara helaran (arak-arakan).

Karnaval fashion pada dasarnya adalah fashion show. Hal mendasar yang membedakan adalah umumnya fashion show disajikan di atas catwalk dan tidak bersifat arak-arakan, sementara karnaval disajikan di jalanan dalam bentuk arak-arakan. Jika Skov dkk. (2009: 2-3) menyebutkan fashion show 
adalah sebuah bentuk seni, dan sebuah catwalk adalah sebuah bagian dari mekanisme promosi industri fashion, maka karnaval fashion juga sebuah bentuk seni, yakni seni pertunjukan yang dapat pula bermotif ekonomi, sebagaimana karnaval kostum Bandung Great Sale 2016.

Sebagai sebuah bentuk seni, karnaval fashion tentu memiliki bentuk dan isi yang memerlukan ruang penyajian. Bentuknya adalah helaran (arak-arakan). Bentuk ini mewadahi materi fashion yang dikarnavalkan. Kualitas bentuk ini secara teoritis dapat dilihat dengan pendekatan formalisme yang lebih menitikberatkan pada persoalan bentuk (Adams, 1996: 6-7). Adapun isinya adalah nilai-nilai yang dituangkan dalam setiap teks fashion yang dikarnavalkan. Persoalan isi ini adalah hal penting, karena wujud fashion adalah salah satu pencitraan mental, yakni pengganti hal sesungguhnya yang oleh Danesi disebut purwarupa (Danesi, 2010: 92). Citra ini bisa dibangun dari rekaman realitas, atau dokumentasi faktafakta manusia, tempat, sesuatu, tindakantindakan dan peristiwa yang melukiskan sesuatu (Leeuwe \& Jewitt, 2001: 4). Oleh karenanya pengemasan bentuk dan isi ini menjadi penting karena keduanya merupakan satu kesatuan organik (Setiawan, Haryono, \& Burham, 2014: 41). Peluluhan keduanya dalam satu entitas akan menjadikan karnaval fashion bukan sekedar arakarakan, namun memiliki citra estetik yang dibangun berdasarkan tema karnaval itu sendiri.

Ruang penyajian arak-arakan adalah runway, jalan besar yang memungkinkan seluruh karya dapat tersajikan di ruang publik sesuai tujuan karnaval itu sendiri. Pilihan runway sendiri cukup penting karena merupakan langkah taktis dan strategis dalam menyajikan karya, sebagaimana perupa memilih ruang pajang tertentu untuk memamerkan karyanya agar memiliki daya ungkit terhadap karyanya.
Ketiga jenis perhelatan di atas merupakan medium dalam meresepsi dan meresensi karya fashion sehingga menjadi salah satu agen utama dalam memperbincangkan karya fashion. Oleh karenaya, perhelatan fashion bukan sekedar menata materi fashion yang dipamerkan dan atau dipertunjukkan, namun juga pekerjaan mengorganisasi dan merekayasa unsur-unsur yang ada di luar ruang pamer atau ruang pertunjukan, yaitu desainer, kurator, dan publik sebagai penikmatnya. Meminjam istilah Susanto (2004: 13), perhelatan fashion ini dapat dianggap sebuah ikatan dan penyambung berbagai hal dan aneka unsur yang ada di dalam ruang besar untuk tujuan dan maksud tertentu.

Objek perhelatan fashion sendiri cukup unik, karena pada umumnya fashion digunakan untuk menyebut mode, yakni gaya pakaian yang populer. Gaya ini tidak terlepas dari gaya hidup yang terus berubah mengikuti trend terbaru. Kecenderungan orang modern yang memuja hasrat tentu akan mengikuti hal tersebut. Oleh karenanya, fashion dan gaya hidup merupakan bagian tidak terpisahkan dari masyarakat modern (Hendariningrum \& Susilo, 2008: 25). Eksistensi keduanya erat melekat, sehingga tidak jarang fashion dipahami sebagai gaya hidup, walaupun tidak semua gaya hidup bisa disebut fashion. Fashion hanyalah salah satu cerminan gaya hidup, karena gaya hidup bukan melulu fashion. Proposisi ini mendasar karena gaya hidup bukanlah sekedar pola tindakan yang membedakan antara orang yang satu dengan lainnya sebagaimana asumsi Chaney (2004: 40). Gaya hidup juga bukan sebatas pengertian hidup yang bergaya, namun juga persoalan pilihan hidup yang terkait dengan ruang dalam manusia, yang jauh dari hiruk-pikuk dan gemerlapnya dunia.

Berdasarkan hal di atas, dapat dikatakan bahwa setiap perhelatan fashion tidak selamanya merayakan gaya hidup, karena bisa 
jadi justru menjadi ajang menyadarkan penikmat, bahwa orientasi hidup bukan gaya hidup. Oleh karenanya, ketika fashion diangkat ke dalam karnaval, bisa saja bukan untuk merayakan gaya hidup, namun justru untuk memaknai hidup. Sudah barang tentu, hal ini terkait dengan bingkai kurasi dari karnaval tersebut.

Meminjam istilah dari Marinis (1993: 1-2), fashion show maupun karnaval fashion adalah pertunjukan yang multi lapis, seperti lapis kostumnya, musiknya, tata panggungnya, performance modelnya, bentuk runway-nya, kreativitas senimannya, konteks penyelenggaraannya, dan masih banyak lagi. Skov dkk. $(2009,17)$ membagi lapis tersebut menjadi dua, yakni yang terkait dengan ruang dan waktu. Hal yang yang terkait dengan ruang adalah setting, catwalk, set dan runway design. Adapun hal yang terkait dengan waktu, adalah music, performance, dan staged appearances.

Sebagai sebuah bentuk pertunjukan yang multi lapis, karnaval fashion tentu melibatkan banyak pihak, seperti penggagas karnaval, kreator kostum (desainer), model, penata artistik panggung, penata musik, penyandang dana, dan lain sebagainya. Masing-masing memiliki kepentingan tertentu terhadap event tersebut. Untuk menyatukan kepentingan ini diperlukan kurator fashion yang tugasnya sama dengan kurator pameran seni rupa pada umumnya, yakni mensenyawakan berbagai kepentingan dalam satu tempat perhelatan karnaval fashion: runway.

Sebagai sosok penting yang berada di balik suksesnya perhelatan fashion, kurator karnaval fashion harus memliki wawasan yang luas sehingga mampu melahirkan makna baru saat fashion ditampilkan di atas runway. Hal ini cukup mendasar karena fashion bisa menjelma menjadi karya seni sebagaimana dipetakan Read (1954: 5), yakni penuh kedalaman, namun di sisi lain harus bisa bertarung dengan dunia kapitalis untuk memenangkan pasar

\section{Kurator Fashion}

Sejarah kata kurator terkait dengan istilah juru kunci, pengawas, dan penjaga. Ia adalah pemimpin yang perannya terkait perawatan dan kontrol adalah inheren (Fowle, 2007: 26). Perkembangan lebih lanjut tentang peran kurator muncul dalam dimensi praktik kurasi seni rupa, karena kerja kurasi mirip seniman yang memproduksi karya seni. Ia seperti sutradara yang memberi peluang munculnya lapisan makna. Kuasa kurator juga dimungkinkan karena ia sebagai penulis, penyeleksi, editor, mediator maupun fasilitator. Oleh karenanya, Carrier (2006: 80) menyebutkan, suksesnya seorang kurator adalah ketika mampu sebagai mediator antara seniman dan publiknya. Dalam konteks museum, Alloway (1996: 222) menyatakan hal yang sama, bahwa kurator yang besar harus menjembatani antara museum sebagai institusi dengan publik sebagai konsumen. Kuasa kurator juga dicatat oleh Janet Wolff, bahwa sebagaimana pemilik galeri, penerbit, distributor, kritikus, dan lain-lain, kurator memiliki kuasa dalam menentukan karya mana yang akan hadir dan dengan cara bagaimana menghadirkannya kepada publik, dan hal ini mempengaruhi kerja kurasi yang mengajak publik memasuki makna wacana yang dihadirkan (Pearce, 1989: 74).

Kerja kurator fashion tidak lepas dari gambaran di atas. Ia bertugas menjembatani antara desainer atau penyelenggaraa pameran fashion dengan publik. Kurator fashion harus berada di depan ketika menjelaskan segala hal yang terkait dengan pameran, seperti tentang karya, nilai pameran yang ditawarkan, serta memaknai kehadiran pameran beserta seluruh karya yang dipamerkan kepada publik. Oleh sebab itu, kurator fashion harus memiliki bekal keilmuan di ranah fashion maupun di luar fashion. Keilmuan di bidang fashion di antaranya adalah praktik produksi hal-hal yang terkait dengan karya fashion, sejarah 
fashion, estetika fashion, semiotika fashion, kearsipan, arkeologi, dan lain sebagainya. Adapun keilmuan di luar fashion yang minimal harus dikuasai kurator fashion adalah kehumasan. Tentu saja keilmuan ini bukan hanya dipahami pada tataran teknis sebagaimana terjadi dalam praktik kehumasan organisasi di Indonesia pada umumnya (Putra, 2008: 188). Hal ini dikarenakan kurator memiliki kewenangan untuk ikut menentukan ke mana pameran akan bergerak. Keilmuan ini diperlukan karena kurator fashion harus mampu merencanakan perhelatan fashion secara detil, menyeleksi karya, dan sebagai supervisor sekaligus, yakni mengawasi, mengarahkan, memastikan, dan mengendalikan segala sesuatunya agar perhelatan fashion berjalan lancar. Keilmuan tersebut juga diperlukan karena kurator fashion harus melakukan riset terhadap karya yang akan dipamerkan. Hasil riset inilah yang kemudian disimpulkan dan diwacanakan ke publik.

Berdasarkan paparan di atas, dapat dikatakan bahwa secara garis besar tugas kurator fashion adalah merencanakan dan melaksanaan suatu perhelatan fashion berdasarkan wacana representasi karya fashion yang dibangun, sehingga tujuan perhelatan fashion dapat tercapai sesuai yang diharapkan.

\section{Kurasi Fashion}

Kerja kurasi pada umumnya dipahami pada wilayah seni rupa, namun berlaku pula untuk fashion (Sullivan, 2005: 138). Oleh sebab itu, praktik kurasi fashion pada dasarnya sama dengan praktik kurasi di dunia seni rupa pada umumnya.

Kurasi bukan sekedar memilih dan menata objek yang dipamerkan dalam ruang tertentu. Kurasi adalah proses panjang kerja kurator dalam rangka membawa karya seniman ke dalam ruang imajinasi, ruang yang dikonstruksi kurator dengan bingkai wacana tertentu sehingga memungkinkan publik memasuki ruang itu selaras dengan arah kurasi yang dibangunnya. Oleh karenanya, memasuki ruang pameran bukan semata melihat objek yang dipamerkan, namun juga menelusuri lorong-lorong pikiran kuratornya. Untuk sampai ke ranah ini kurator dihadapkan pada persoalan objek seni yang dipamerkan itu sendiri (bentuk dan isi), maupun hal lain yang terkait dengan tujuan pameran, seperti sponsor, pemilik galeri dan lain sebagainya. Guna menjawab persoalan ini, seorang kurator tentunya harus memiliki kemampuan dalam menilai karya sesuai wacana yang ia bangun, serta kemampuan mengkoordinasikan semua yang terlibat dalam pameran agar tujuan pameran tercapai. Kurator juga harus mampu mempresentasikan karya yang dipamerkan melalui tulisan yang bernas maupun secara lisan di depan publik.

Sebagaimana kurasi dalam dunia seni rupa, kurasi fashion bukanlah hanya persoalan memilah dan memilih busana/kostum yang akan dipamerkan/dikarnavalkan. Kurasi fashion adalah upaya sistematis dalam merekayasa berbagai unsur dalam perhelatan fashion agar wacana dan materi yang disajikan terpresentasikan sesuai tujuan karnaval itu sendiri, seperti motif ekonomi, edukasi, estetis, dan lain sebagainya. Proposisi ini cukup mendasar karena pameran [dan juga karnaval] merupakan sebuah sistem strategis representatif ( $\mathrm{Su}$ santo, 2004: 10).

Sebagai bentuk representasi, Furst menyebut pameran memiliki dua tipe utama dilihat dari gaya suatu pameran. Pertama gaya dengan pendekatan estetik. Ciri gaya ini lebih berkonsentrasi pada pandangan bahwa objek memiliki nilai intrinsik yang dengan sendirinya berbicara untuk dirinya sendiri dan penekanan diberikan kepada hak dari objek untuk berdiri sendiri. Kedua gaya dengan pendekatan rekonstruktif. Ciri gaya ini menghadirkan objek sebagai sesuatu yang memiliki arti secara etnografi dan berusaha untuk menginformasikan bu- 
daya latarnya (Read, 1954: 99). Meminjam pendapat Frust ini, karnaval fashion sebagai bentuk representasi tentu bisa dibangun dari kedua gaya tersebut. Pilihan mana yang dipilih tentu didasarkan pertimbangan bingkai kurasi yang dibangun kurator.

\section{Bingkai Kurasi JFC}

Perhelatan karnaval tahunan yang digelar JFC, merupakan satu kesatuan event JFC International Exhibition (JIE). Perhelatan tahunan ini menyedot perhatian publik nasional maupun internasional yang diliput ratusan media dari dalam dan luar negeri. Untuk selanjutnya kegiatan pameran tidak dibahas, karena fokus kajian diarahkan pada kurasi fashion karnavalnya, yang terdiri dari Kid Carnival, Artwear Carnival, WACI Carnival (Wonderful Archipelago Carnival Indonesia) dan Grand Carnival. WACI Carnival tidak dibahas karena tidak dikurasi oleh JFC sebagaimana Kid Carnival, Artwear Carnival, dan Grand Carnival.

Karnaval yang diproduksi oleh manajemen JFC adalah karnaval berkualitas, baik dari sisi karya, penyajian, maupun penyelenggaraannya. Hal inilah yang membedakan dengan karnaval yang diselenggarakan oleh kota lain di Indonesia. Dynand Fariz selaku presiden JFC menegaskan, bahwa karnaval yang diselenggarakan oleh kota lain hanya untuk euforia, kurang perhatikan kualitas sebagaimana dilakukan oleh JFC. Memang ada kota lain yang sudah spesifik seperti Solo, namun dari sisi konsep hingga penyajiannya JFC yang terbaik hingga menjadi karnaval nomor 1 di Asia, dan nomor 3 di dunia (wawancara, 27 Juli 2017).

Salah satu upaya yang dilakukan JFC agar melahirkan karnaval yang berkualitas adalah melalui proses penciptaan karya dengan landasan konsep yang matang serta penyajian berkelas dunia. Di sini, secara tidak sadar JFC telah membuat standar pengkurasian karya kostum karnaval berkelas dunia.
JFC menyajikan karya karnavalnya di atas runway terpanjang di dunia, yakni 3,6 km. Untuk JFC-16, Kid Carnival, Artwear Carnival, dan WACI Carnival menempuh jarak kurang lebih 1,8 km, mulai dari Jalan Sudarman, Jalan Sultan Agung, Jalan Gajah Mada, dan finish di LIPPO MALL Jember. Adapun untuk Grand Carnival tetap seperti tahun sebelumnya, yakni menempuh jarak 3,6 km, mulai dari Jalan Sudirman, Jalan Sultan Agung, Jalan Gajah Mada dan berakhir di Gedung Serbaguna.

Agar perhelatan karnaval fashion-nya mencapai tujuan yang diharapkan, JFC membuat bingkai kurasi dalam tujuh lapis yang menjadi tahapan kurasi, yakni: penentuan tema, penjemputan peserta pelatihan, proses produksi, preview atau presentasi, penjurian, dan gladi kotor serta gladi bersih sebelum penyajian karya (lihat gambar 1).

Lapis/tahap pertama adalah penentuan tema karnaval. Penentuan tema adalah hal penting karena setidaknya tiga hal. Pertama, tema merupakan ruh yang akan menjiwai pameran. Kedua, tema akan mengarahkan tujuan dan misi pameran yang akan dicapai. Ketiga, melalui tema yang dibangun, jenis karya yang akan disajikan akan lebih mudah ditentukan. Tentu saja yang ketiga ini adalah ketika karnaval digelar berangkat dari karya mengikuti tema, bukan tema mengikuti karya. Oleh sebab itu, melalui tema karnaval secara tersirat telah nampak dalam konteks apa karnaval dihadirkan, untuk siapa, dan apa tujuannya.

JFC menyadari betul pentingnya tema karnaval karena merupakan salah satu strategi "menjual" karnavalnya. Hal ini mendasar karena fashion adalah persoalan gaya hidup, style, dan trend yang memiliki pasarnya sendiri. Bukan hanya itu, fashion adalah alat dan pemelihara mekanisme kapitalisme sebagaimana dipahami Craik (Valentin, 2010: 77). Oleh karenanya, wajar ketika Metro TV dalam acara Big Circle tanggal 30 Juli 2017 memberi tajuk: JFC 


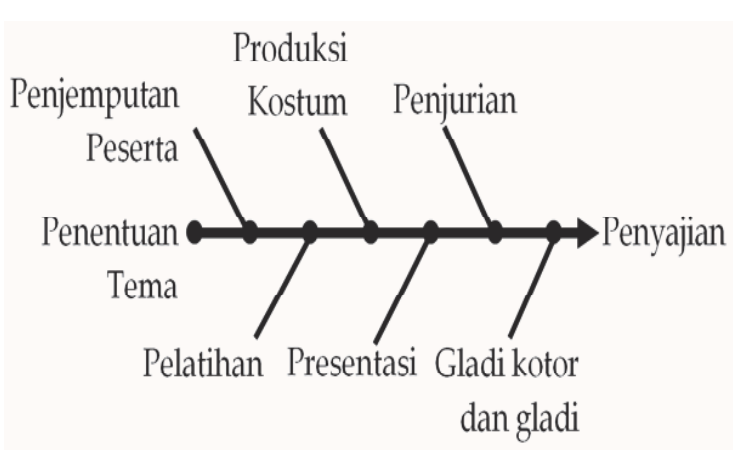

Gambar 1: Bagan bingkai kurasi fashion JFC

Penggerak Ekonomi. Pada acara yang dihadiri Deputi P3N Kemenpar RI Esthy Reko Astuty itu disebutkan, bahwa JFC telah menjadi Destination Branding. Sudah barang tentu semangat karnaval yang dibangun JFC bukanlah dalam kerangka kapitalisme murni. Jika ada perputaran ekonomi dalam perhelatan tersebut adalah akibat, bukan tujuan utama. Pada titik ini, JFC telah mengimplementasikan proposisi Djokosarwono, bahwa kewibawaan seni ialah kecakapannya memberi inpsirasi, entah untuk pertumbuhan seni itu sendiri, entah untuk pertumbuhan saudara-saudaranya (Susanto, 2003: 24).

Tema yang diangkat untuk JFC ke15 dan ke-16 cukup strategis dan mampu mangangkat pamor JFC. Tema untuk JFC ke-15 adalah Revival. Tema ini dipilih untuk menggambarkan kebangkitan Indonesia di berbagai bidang yang diwujudkan dalam 10 sub-tema defile, yakni: Garuda, Hortus, Technocyber, Woods, Paradisaea, Refugees, Ocean, Chandelier, Olympic dan Barong. Defile Garuda mewakili kebangkitan nilai dan semangat nasionalisme. Kebanggaan bahwa Indonesia adalah negara besar yang berdaulat. Defile Woods mengingatkan bangsa ini untuk menggaungkan pelestarian hutan dan bangkit melawan pembakaran hutan. Defile Chandelier mewakili kebangkitan transparansi informasi. Refugees dihadirkan sebagai simbol kebangkitan nilai-nilai kemanusiaan global. Paradisaea mewakili semangat kebangkitan untuk menjaga ke-

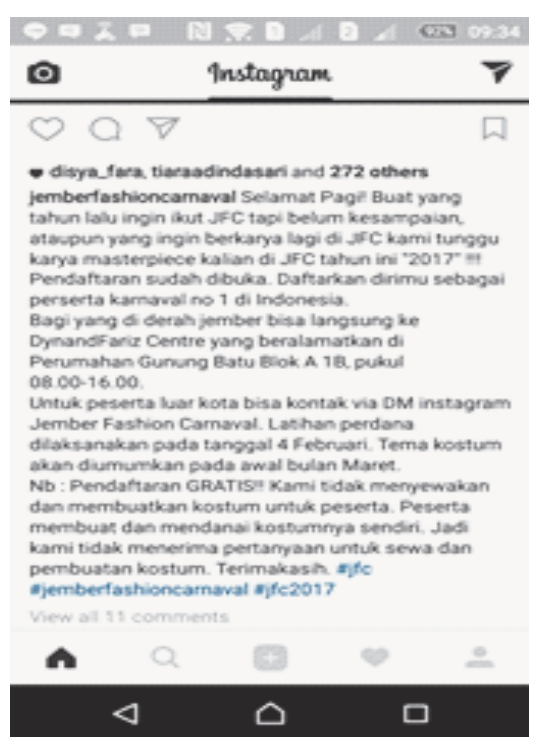

Gambar 2. Undangan kepada calon peserta karnaval JFC-16 (2017) melalui instagram JFC (Sumber: Nadia Rachmaya Ningrum Budiono, 2017)

lestarian satwa langka Indonesia. Ocean mewakili semangat kebangkitan di dunia maritim. Olympic mewakili semangat kebangkitan olah raga, tidak hanya bagi insan olah raga namun juga bagi seluruh lapisan masyarakat Indonesia. Hortus mewakili semangat kebangkitan untuk mengeksplorasi dan mengembangkan tanaman unggulan yang siap bangkit dan berpotensi di perdagangan dunia. Technocyber mewakili semangat kebangkitan di bidang teknologi, dan defile Barong kebangkitan seni budaya Indonesia.

Berbeda dengan tema sebelumnya yang lebih merepresentasikan kebangkitan bangsa, tema JFC ke 16 (2017) lebih menonjolkan kiprah dan prestasi JFC di ajang perhelatan fashion dunia sebagai wakil Indonesia, yakni Victory, Unity in diversity. Tema ini dipilih untuk yang melambangkan kemenangan Indonesia atas diraihnya the best national costume, baik dalam male dan female peagant di berbagai kompetisi dunia yang terinspirasi dari kekayaan budaya nusantara, yakni Best National Costume Mister International 2010 di Jakarta, Mystical Toraja (Best National Costume Manhunt International 2011 di Korea Selatan); King 


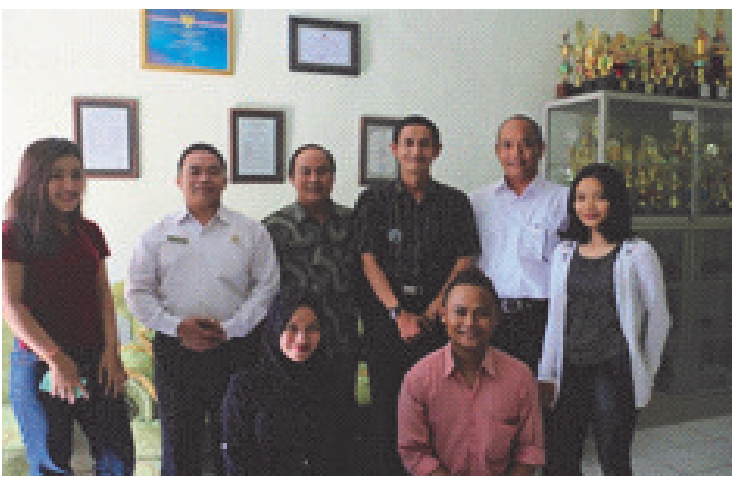

Gambar 3. Peserta dari Prodi Tata Rias dan Busana ISBI Bandung membantu manajemen JFC melakukan sosialisasi JFC ke MAN 1 Jombang (Foto: Shinta Sartika, 2016).

of Papua (Best National Costume Mister Universe Model 2011 Dominican Republic); The Cronicle of Borobudur (Best National Costume Miss Universe 2014 di Miami Florida USA); Princes of Borneo (Best National Costume Miss Supranational 2014 di Warsawa Polandia); Tale of Siger Crown (Best National Costume Miss International 2014 di Tokyo Jepang) Wonderful of Betawi (Best National Costume Miss Tourisme International 2016 di Malaysia); Mythical Toraja (Best National Costume Miss Supratarunal 2016 di Polandia), dan Unity in diversity yang merupakan Top Five National Costume Miss Universe 2016 di Filipina. Tema ini kemudian diwujudkan dalam delapan defile, yakni: Sriwijaya, Sulawesi, Borneo, Lampung, Betawi, Papua, Borobudur, dan Bali.

Tema di atas tentu dikonstruksi dengan sederet riset dan landasan filosofi yang oleh Valentin (2010: 78) dikategorikan dua level, yakni immaterial dan material. Immaterial adalah tataran nilai, konsep, atau gagasan tertentu yang akan ditawarkan, dan material adalah kristalisasi dari immaterial tersebut yang diwujudkan dalam benda seni (fashion). Berangkat dari sini dapat dijelaskan, bahwa tataran immaterial dari JFC ke-15 adalah nilai-nilai kebangkitan Indonesia di berbagai bidang dan yang diwujudkan dalam 10 sub-tema devile Garuda, Hortus, Technocyber, Woods, Paradisaea, Refugees, Ocean, Chandelier, Olympic dan Barong.

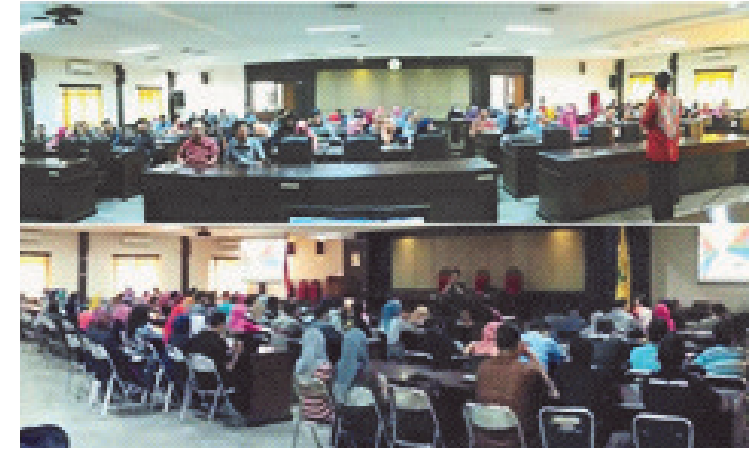

Gambar 4: Coaching school di Universitas Negeri Jember (Sumber: dokumentasi JFC, 2016)

Nilai-nilai tersebut dianggap penting guna membangkitkan semangat anak bangsa dari berbagai bidang demi kemajuan bangsa Indonesia. Adapun tataran immaterial dari JFC ke-16 adalah representasi kemenangan dan keberhasilan bangsa Indonesia dalam menyatukan berbagai perbedaan dalam bingkai Negara Kesatuan Republik Indonesia, serta potensi kekayaan budaya nusantara sebagai pijakan keunggulan bangsa. Hal ini diwujudkan dalam national costume yang terinspirasi dari kekayaan budaya nusantara dan telah mengangkat citra Indonesia di dunia internasional.

Lapis/tahap kedua adalah penjemputan atau mengundang calon peserta JFC. Penjemputan ini salah satunya melalui instagram JFC. Inti undangan berisi pemberitahuan bahwa pendaftaran untuk mengikuti JFC telah dibuka disertai keterangan cara pendaftaran serta tema JFC yang akan diumumkan kemudian (lihat gambar 2). Pada JFC ke-15 penjemputan juga dilakukan dengan mendatangi sekolah-sekolah untuk sosialisasi pelaksanan JFC (lihat gambar 3). Selain itu juga diadakan coaching school, yakni memberi pelajaran dan penyuluhan kepada siswa dari berbagai sekolah dan perguruan tinggi yang telah bekerjasama dengan pihak JFC mengenai kegiatan yang harus dilakukan sebelum JIE dilaksanakan (lihat gambar 4).

Calon peserta sendiri dapat digolong- 


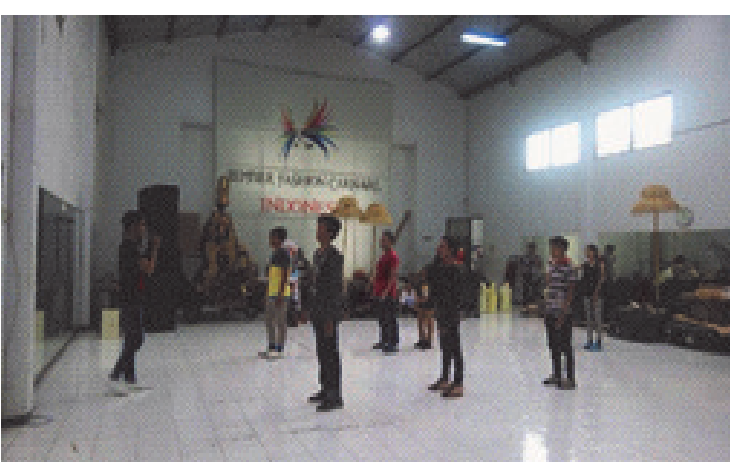

Gambar 5. Pelatihan menari di markas JFC (Foto: Suharno, 2016)

kan menjadi dua, yakni senior dan yunior. Senior adalah mereka yang pernah ikut dalam JFC sebelumnya, dan junior adalah mereka yang baru pertama kali ikut JFC. Peserta ini bisa perorangan, atau kelompok seperti komunitas, sekolah, dan lain sebagainya. Adapun peserta dari luar Jember wajib residensi di Jember kurang lebih 3 bulan untuk mengikuti seluruh proses kegiatan JFC sebagaimana dijalankan oleh lima mahasiswa Prodi Tata Rias dan Busana ISBI Bandung di JFC ke-15 dan dua mahasiswa di JFC ke-16. Hal ini diperlukan agar karya yang dibuat terkontrol oleh JFC.

Lapis/tahap ketiga adalah pelatihan. Sebelum membuat kostum seluruh peserta mendapatkan pelatihan mendesain kostum karnaval berdasarkan moodboard inspirasi dan prototype yang telah dibuat JFC, pelatihan make up, pelatihan berjalan di atas catwalk dan run way, menari, dan lain sebagainya (lihat gambar 5,6,7). Pelatihan ini diperlukan karena peserta harus mengenakan kostum yang dirancang sendiri mulai dari presentasi, penjurian, hingga saat karnaval. Peserta yang masih duduk di bangku TK, SD, SMP, dan SMU mendapatkan tutorial dari tim JFC melalui guru pendamping. Pada proses pelatihan ini JFC tidak memungut biaya apapun.

Lapis/tahap keempat adalah produksi karya yang seluruh biayanya ditanggung peserta JFC. Pada tahap ini setiap peserta didampingi oleh leader masing-masing defile

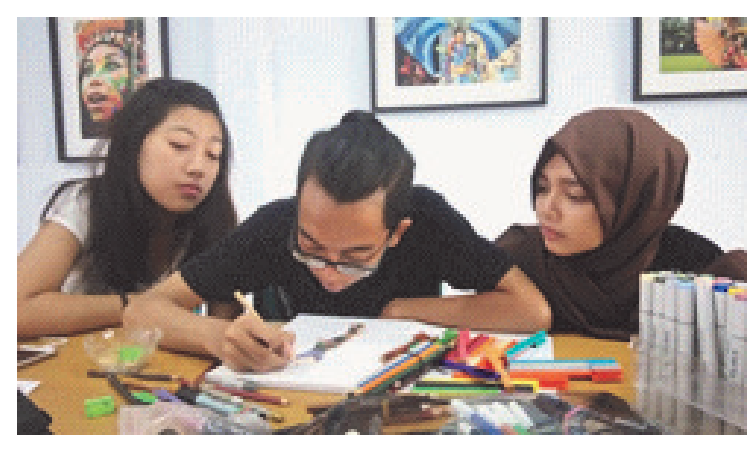

Gambar 6. Peserta mendapatkan pelatihan mendesain dari tim kreatif JFC (Foto: Sri Asyani, 2016)

yang ditunjuk JFC. Leader adalah senior JFC yang terpilih karena harus mendampingi peserta dalam mewujudkan karyanya sehingga hasilnya benar-benar menjadi karya karnaval kelas dunia. Pada saat produksi, JFC memberikan rambu-rambu agar peserta mematuhi kriteria yang ditentukan terkait kostum yang dibuat. Contohnya, secara umun kostum tidak boleh memperlihatkan paha. Untuk defile Bali di JFC ke-16 (2017), peserta tidak boleh mengangkat Garuda Wisnu Kencana (GWK), barong, rangda, kemboja, dan kenanga. Warna utama yang boleh digunakan adalah emas, putih, hitam, dan kuning. Warna merah boleh ditambahkan untuk detil kostum. Adapun yang harus ada dalam bagian kostum adalah kain kotak-kotak khas Bali (kain poleng) dan prada Bali. Keduanya boleh digunakan, salah satu, atau dikombinasikan (Sabrina, 2017). Pembatasan ini terkait dengan norma dan alasan teknis karena di JFC sebelumnya telah mengangkat Barong dengan komposisi warna yang dilarang tersebut. Adapun GWK dilarang kemungkinan karena dianggap sebagai karya seni modern, bukan seni tradisi.

Lapis/tahap kelima adalah presentasi karya, yakni penilaian awal terhadap progress wujud karya. Presentasi ini dilaksanakan kurang lebih sebulan sebelum hari pelaksanaan. Pada tahap ini seluruh peserta diwajibkan mengenakan karyanya yang rata-rata baru selesai sekitar $65 \%-75 \%$, dan 


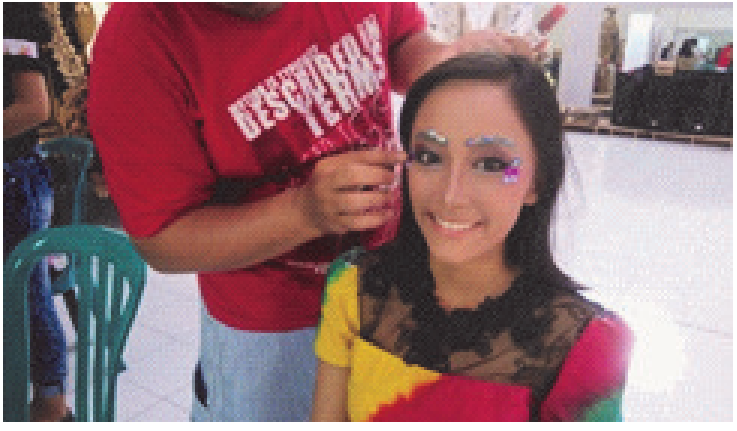

Gambar 7: Tim kreatif JFC melatih tata rias (Foto: Sri Asyani, 2016)

menyajikannya di markas JFC di hadapan tim penilai yang ditunjuk JFC (lihat gambar 8). Bentuk penyajiannya berupa fashion show per-defile diringi musik yang nantinya dipakai saat show yang sesungguhnya. Setelah satu defile menyajikan karya, kemudian dievaluasi oleh tim juri, baik dari bentuk kostum dan detilnya, maupun ekspresi penyajiannya. Jika terjadi kesalahan fatal dalam bentuk-misalnya karya tidak sesuai desain kostum karnaval-peserta yang bersangkutan diberi kesempatan selama kurang lebih tiga hari untuk memperbaiki dan menyajikan ulang di tempat yang sama. Jika kesempatan ini gagal dimanfaatkan, maka peserta yang bersangkutan dianggap gugur.

Kurang lebih seminggu kemudian dilakukan presentasi ke-2 di central runway yang sesungguhnya, yakni Central Park Jember (lihat gambar 9). Pada tahap ini seluruh peserta diwajibkan menampilkan karyanya yang sudah diperbaiki di depan publik dalam bentuk fashion show per-devile. Hal ini dilakukan untuk mengecek kekuatan kostum, kemampuan fisik berjalan di atas runway dan ekspresi di depan publik yang sesungguhnya.

Uji kostum ini diperlukan untuk evaluasi lebih jauh agar saat pelaksanaan semua berjalan dengan baik. Pada JFC-16, presentasi yang kedua tidak dilaksanakan karena padatnya acara JFC. Meski demikian hal ini tidak mengurangi kualitas karya yang ditampilkan karena progres perkembangan

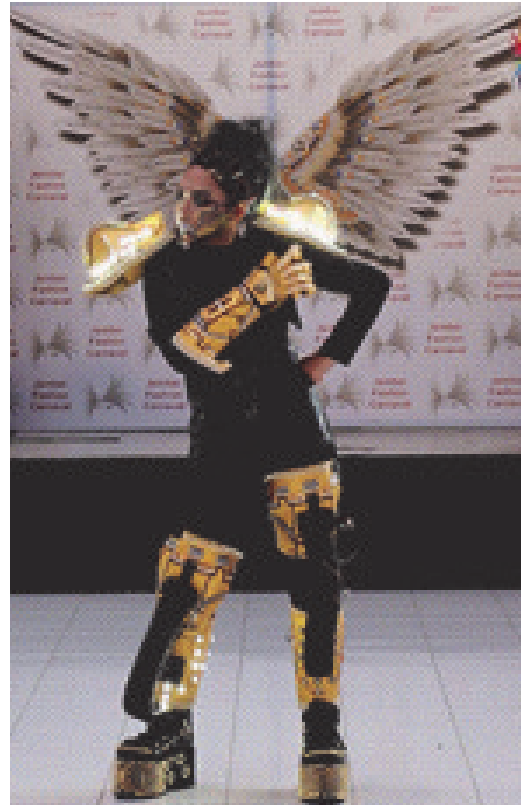

Gambar 8: Presentasi pertama Nadia Rachmaya

Ningrum Budiono (defile Technocyber)

di markas JFC (Foto: Shinta Sartika, 2016)

karya selalu dalam pengawasan leader masing-masing.

Lapis/tahap keenam adalah grand jury yang dilakukan di aula Eidelweis Cempaka Hotel Jember dan dipimpin langsung oleh Dynand Fariz (lihat gambar 10). Dewan juri terdiri dari model profesional, senior JFC yang telah mendapatkan award dan menjadi istruktur serta bagian dari tim kreatif JFC Penjurian dilakukan dengan sangat ketat dan detil. Materi yang dinilai adalah bentuk kostum itu sendiri, tata rias, dan ekspresi perancang saat penyajian karya sesuai karakter kostum yang dikenakan (performance). Penilaian kostum selain dilihat dari sisi bentuk yang khas karnaval (bervolume besar), juga detil serta kerapihan dari setiap kostum dari berbagai sisi atau 3600 (lihat gamber 11). Adapun ketentuan umum saat penjurian adalah peserta wajib datang tepat waktu sesuai jadwal yang ditentukan JFC. Jika terlambat akan didiskualifikasi, namun tetap boleh tampil dalam karnaval jika memenuhi kriteria JFC. Jika dalam penjurian ini ada peserta yang dinyatakan tidak layak, peserta yang bersangkutan harus memperbaiki dan melakukan presentasi ulang di 


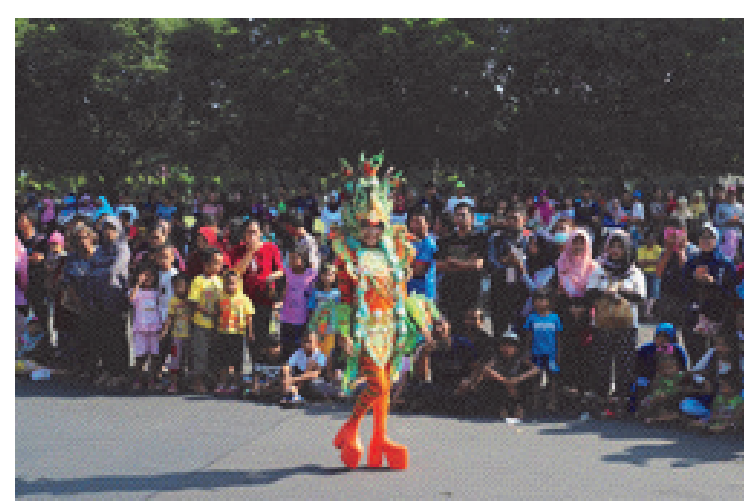

Gambar 9: Presentasi ke dua Shinta Sartika (JFC-15, defile Ocean) di runway Central Park Jember (Foto: Nadia R, 2016)

markas JFC. Jika tetap tidak memenuhi persyaratan peserta yang bersangkutan tidak diperbolehkan mengikuti karnaval.

Lapis/tahap ketujuh adalah gladi kotor dan gladi bersih yang dipimpin langsung oleh presiden JFC. Gladi kotor dqan gladi bersih ini menjadi bagian penting dari kurasi karena terkait dengan penyajian karya. Ibarat ruang galeri, runway adalah ruang pajang fashion yang penataannya memerlukan kejelian akan wujud kostum sehingga ketika karnaval disajikan akan nampak keserasian komposisi dari sisi bentuk, ukuran, dan warna kostum. Gladi bersih di JFC bukan hanya persoalan jalan di atas runway, namun bagaimana peserta karnaval secara total mampu mengekspresikan karyanya di depan publik saat karnaval termasuk ratusan media dari dalam dan luar negeri secara terstruktur rapi (lihat gambar 12).

Seluruh rangkaian kurasi di atas diterapkan untuk peserta kategori Kid Carnival, Artwear Carnival, maupun Grand Carnival. Adapun WACI Carnival tidak dikurasi karena merupakan produk Asosiasi Karnaval Indonesia dari perwakilan provinsi. Adapun urutan penyajian karnavalnya adalah Kids Carnival (hari pertama), Artwear Carnival (hari kedua), WACI Carnival (hari ketiga), dan hari terakhir sebagai acara puncak adalah Grand Carnival.

Ketujuh tahap di atas dilakasanakan

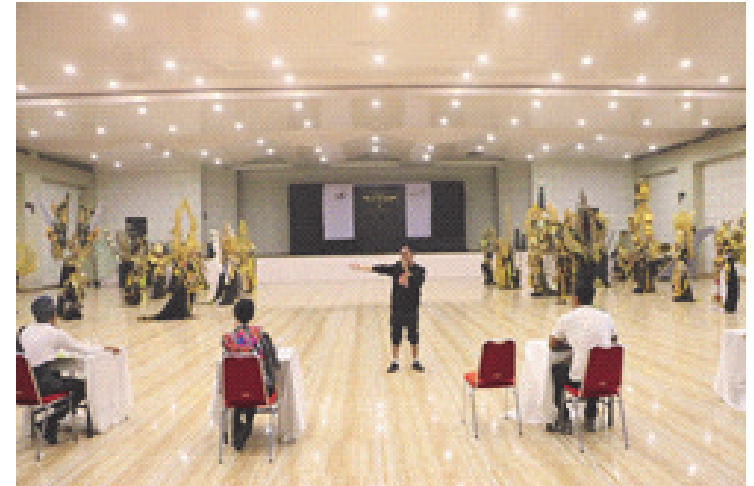

Gambar 10: Presiden JFC memimpin langsung jalannya Grand Jury JFC-16

(Foto: Cahyadi Dewanto, 2017)

secara sistemik dan terukur, sehingga menjadi pola kurasi yang tingkat keberhasilannya tidak diragukan lagi.

Selanjutnya, sebagai rangkaian terakhir dari ritual perhelatan JFC adalah awarding, yakni pemberian penghargaan bagi peserta JFC kategori junior maupun senior. Acara ini waktunya tidak bisa ditentukan dengan pasti karena padatnya jadwal kegiatan JFC.

Awarding dilaksanakan di aula Eidelweis Cempaka Hotel Jember dan dipimpin langsung oleh Dynand Fariz. Penghargaan diberikan kepada peserta terbaik di setiap devile, yakni dari sisi best performance dan keunikan kostumnya. Oleh sebab itu dalam setiap devile akan mendapataan penghargaan best performance dan unique costume.

Penghargaan Unique Costume diberikan kepada peserta yang karyanya paling unik. Adapun penghargaan Best Performance diberikan kepada peserta yang didasarkan bukan hanya pada keunikan karya kostumnya, namun juga totalitas ekspresinya saat mengenakan kostum tersebut. Sudah barang tentu ekspresi ini terkait dengan karakter dari kostum yang dibuatnya. Meminjam istilah dalam tari gagrag atau gaya Mataraman, penghargaan Best Performance diberikan kepada peserta yang dalam membawakan kostumnya telah sampai pada pertemuan titik wiraga, wirasa, dan wirama (periksa Suryadiningrat, 1934: 3). 


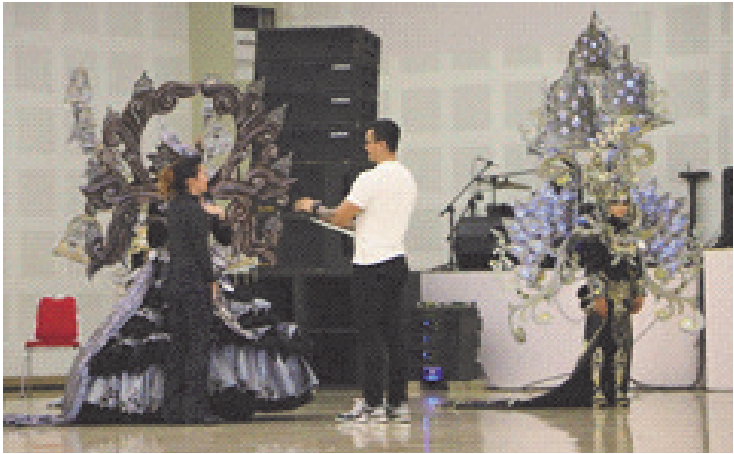

Gambar 11: Salah satu juri mewancarai Anandayu, mahasiswi Prodi Tata Rias dan Busana yang mengikuti JFC-16 defile Borobudur (Foto: Cahyadi Dewanto, 2017)

\section{SIMPULAN}

Secara substantif, kurasi fashion di JFC sama dengan kurasi di dunia seni rupa pada umumnya. Hal yang membedakan, objek adalah ranah seni pertunjukan yang multi lapis, sehingga lebih rumit. Kurator harus dengan cermat mempertimbangkan runway yang digunakan untuk karnaval agar bersih secara fisik maupun dari orang yang lalu lalang. Hal ini bukan perkara mudah karena memerlukan koordinasi dengan pihak-pihak terkait. Kerumitan lain juga muncul karena yang dikurasi bukan benda mati, yakni ekspresi model/desainer sekaligus model yang membawakan kostum karnaval. Ekspresi model yang dilatih sejak awal bisa saja hancur karena situasi dan kondisi yang tdak mendukung, seperti hujan, demam panggung, grogi di depan media, dan lain sebagainya. Hal ini tentu tidak ditemukan dalam praktik kurasi di dunia seni rupa.

Berdasarkan pengamatan lapangan dan analisis dari proses hingga awarding ", dapat dikatakan bahwa secara garis besar aspek utama yang dikurasi oleh JFC adalah dua hal, yakni bentuk kostum dan penyajiannya (performance). Hal yang pertama harus sesuai dengan tema, memenuhi rambu-rambu dan kriteria kostum karnaval yang ditetapkan JFC (bervolume besar, detil, dan rapi 3600). Aspek bentuk ini terkait dengan tata rias yang diterapkan, karena tata rais dan

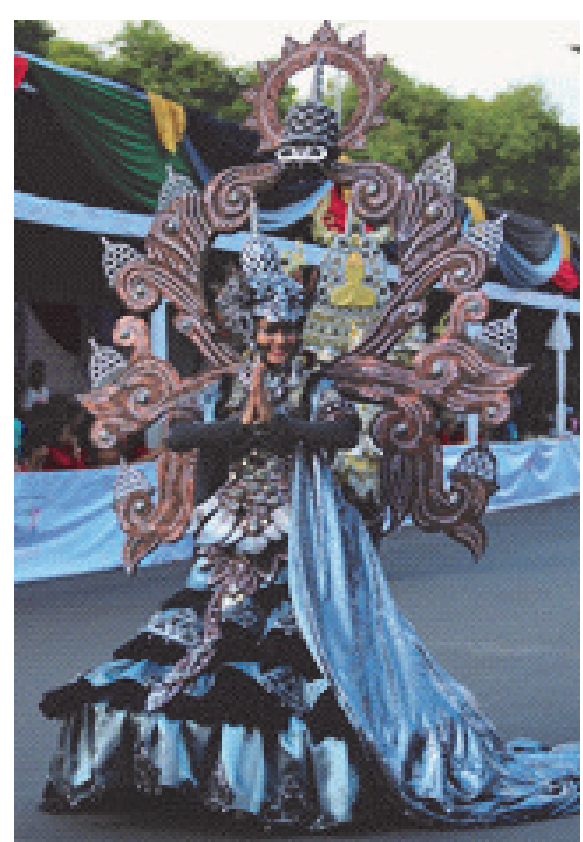

Gambar 12. Anandayu berpose di depan Media Zona A saat Grand Carnival. Ketepatan pose ini berkat gladi kotor dan gladi bersih

(Foto: Cahyadi Dewanto, 2017)

bentuk kostum merupakan satu kesatuan makna. Hal yang kedua berkaitan dengan totalitas dan ekspresi peserta saat menyajikan karyanya, sehingga karakter kostum muncul sebagaimana yang diharapkan.

Kedua aspek tersebut menjadi pola kurasi dengan tujuh lapis/langkah utama, yakni penentuan tema, penjemputan peserta, pelatihan, produksi, presentasi, penjurian, dan gladi kotor serta gladi bersih sebelum akhirnya penyajian karya. Pola ini telah mengantarkan Jember menjadi Kota Karnaval, serta menjadikan Indonesia memiliki karnaval terbesar ke-3 dunia setelah Notting Hill (USA) dan France (Reunion). Meskipun secara de facto JFC tidak menyebut apa yang dilakukan sebagai kurasi fashion, sudah barang tentu hal ini bukan persoalan krusial untuk diperdebatkan, karena inti semua pelatihan dan ramburambu yang diberikan JFC kepada peserta karnaval adalah dalam rangka melahirkan karya kostum karnaval kelas dunia dalam bingkai tema yang diusung JFC.

Pola bingkai kurasi fashion yang dilakukan JFC kiranya bukan hanya menjadi 
catatan penting dalam perjalanan karnaval di Indonesia yang berkelas dunia, namun sekaligus merupakan model kurasi fashion yang dapat dijadikan rujukan penyelenggaraan karnaval bagi kota-kota lain di Indonesia. Berangkat dari sini dapat dikatakan, bahwa hasil penelitian ini benar-benar memiliki nilai kebaruan.

\section{Ucapan Terima Kasih}

Penulisan ini tidak lepas dari bantuan tim manajemen JFC serta mahasiswa peserta JFC ke-15 dan ke-16 dari Prodi Tata Rias dan Busana ISBI Bandung. Oleh sebab itu, ucapan terimakasih penulis sampaikan kepada mas Dynand Fariz, mas David, mas Suyanto, dan mas Iwan atas kemudahan yang diberikan kepada penulis. Kepada tim prodi Tata Rias dan Busana, yakni Puad, Riska, Nadia, Sri, Shinta, Dayu, dan Sabrina, terimakasih atas waktunya, karena di sela-sela sebagai peserta karnaval membantu menggali data penelitian ini.

\section{Daftar Pustaka}

Cahyani, I. D. (2015). Implementasi Jember Fashion Carnaval sebagai Bagian dari City Branding Kabupaten Jember. Ilmu Komunikasi, 2, (4), 142 - 156.

Denisa, L., Piliang, Y. A., Widodo P., Damayanti, N. Y. (2016). Fenomena Intertekstualitas Fashion Karnaval di Nusantara. Panggung, 26 (6), 430-443.

Hendariningrum, R. dan Susilo, M. E. (2008). Fashion dan Gaya Hidup: Identitas dan Komunikasi. Ilmu Komunikasi, 6 (2), 25-32.

Jannah, R. (2012). Jember Fashion Carnival: Konstruksi Identitas dalam Masyarakat Jaringan. Masyarakat, 17 (2), 135-152.

Palmor, L. (2015). Proto-Fashion Theorist. Revista Forma, 11, 39-50.

Putra, I. G. N. (2008). Konteks Historis Praktik Humas di Indonesia. Ilmu Komunikasi, 6 (3), 178-190.
Adams, L. S. (1996). The Methodologies of Art. Colorado: Westview Press.

Alloway, L. (1996). The Great Curatorial DimOut. In Thinking about Exhibitions. R. Greenberg, B. W. Ferguson and S. Nairne. London, New York: Routledge.

“Big Circle Metro TV: JFC Penggerak Ekonomi". Tayang tanggal 30 Juli 2017.

Breward, C. (2003). Fashion. New York: Oxford University Press.

Brouwer, M.A.W. (1984). Fenomenologi. Jakarta: Gramedia

Buick, N. (2012). Framing Curation: A Theoretical, Historical and Practical Perspective. Submitted in fulfilment of the requirements of the degree of Doctor of Philosophy, Creative Industries Faculty Quesland University of Technology.

Carrier, D. (2006). Museum Skepticism: A History of the Display of Art in Public Galleries. Durham: Duke University Press.

Chaney, D. (2004). Lifestyle Sebuah Pengantar Komprehensif. Yogyakarta: Jalasutra.

Craik, J. (2009). Fashion the Key Concept. New York: Berg.

Creswell, J. W. (1998). Qualitatif Inquiry and Research Design. California: Sage Publications, Inc.

Danesi, Marcel. (2010). Pesan, Tanda dan Makna: Buku Teks Dasar Mengenai Semiotika dan Teori Komunikasi. Terjemahan Evi Setyarini dan Lusi Lian Piantari. Cetakan pertama. Yogyakarta: Jalasutra.

Fowle, K. (2007). “Who Cares? Understanding the Role of the Curator Today". In S. Rand and H. Kouris, Cautionary Tales: Critical Curating. New York: Apexart.

Hujatnikajennong, A. (2015). Kurasi dan Kuasa: Kekuratoran dalam Medan Senirupa Kontemporer di Indonesia. Tangerang: Marjin Kiri.

Klein, A. From the Canvas to the Runway". 
Retrieved May 16, 2015, from https:// runinheels.com/tag/anne-klein/.

Leeuwen, T. V., dan Jewitt, C. (2001). “Introduksi" in Theo Van Leeuwen dan Carey Jewitt, ed. Handbook of Visual Analysis. London: Sage Publications Ltd.

Marinis, M. d. (1993). The Semiotic of Performance. Bloomington and Indianapolis: Indiana University Press.

Pearce, S. M. ed. (1989). Museum Studies in Material Culture. London; New York: Leicester University Press.

Read, H. (1954). Art and Industry: The Principles of Industrial Design, New York: Horison Press.

Setiawan, D., Haryono, T., dan Burham, M. (2014), Prinsip Estetika Pakaian Cosplay Yogyakarta: Fantasi dan Ekspresi Desain Masa Kini. Panggung, 24 (1), 39-48.

Skov, L., Skjold, E., Moeran, B., Larsen, F., and Csaba, F. F. (2009). Creativity at Work: The Fashion Show as an Art Form. Copenhagen: Copenhagen Busines School.
Sullivan, G. (2005). Art Practice as Research: Inquiry in the Visual Arts. London: Sage Publications.

Suryadiningrat. (1934). Babad Lan Mekaring Djoged Djawa. Yogyakarta: Kol Buning.

Susanto, M. (2003). Membongkar Seni Rupa. Yogyakarta: Jendela.

------------. (2004). Menimbang Ruang Menata Rupa: Wajah dan Tata Pameran Seni Rupa. Yogyakarta: Galang Press. Troy, N. (2006). Piet Mondrian's Last Thoughts In Late Thoughts: Reflections on Artist And Composers at Work. Los Angeles: Getty Publications.

Tsotsos, E. N. (2014). Presenting the Fashion Object: Analyzing the exhibition Fashioning the Object: Bless, Boudicca, (MA). The University of Western Ontario London, Ontario, Canada.

Valentin, M. M. (2010). On The Nature on Trends: A Study of Trend Mechanisms in Contemporary Fashion. Denmark: Denmarks Designskoles Printcenter Paper. 